\title{
Escritas de mulheres: cotidiano, força e rebeldia
}

Da mulher emana a força mágica da criação.

(Paulina Chiziane)

Todos os dias eu escrevo. Sento no quintal e escrevo.

(Carolina de Jesus)

Adélia Prado, em seu poema de abertura do livro Bagagem, encara a condição de escritora como destino: "o que sinto escrevo. Cumpro a sina./Inauguro linhagens, fundo reinos/(dor não é amargura)" (PRADO, 1979). A mulher, que funda reinos, nações ou sociedades, compõe o quadro de personagens e escritoras das literaturas da língua portuguesa. Entre as personagens, tanto o exílio de Iracema, personagem de Alencar, quanto a mulher africana, personagem Louca de Serrano, são exemplo disso. Se esta é "voz carregada de solidão, dor, negação, rebeldia inconformismo", "resistência à marginalização feminina nas e pelas práticas sociais hegemônicas" (BRAGA, 2014.), aquela exila-se para fundar a nação e dar a luz a Moacir, o filho da dor. Na visão romântica e contemporânea, no Brasil, em África ou em Portugal, a personagem mulher-dor, na literatura e na sociedade, rompe as fronteiras que the são impostas e se desdobra em mãe, intelectual, escritora, e sobrevivente.

Paulina Chiziane, em seu testemunho escrito em 1992 e publicado em meados de 1994 por iniciativa da UNESCO, em fase dos preparativos da Conferência Internacional sobre a Mulher, Paz e Desenvolvimento, realizada em Pequim em 1995, responde à pergunta sobre como a sociedade recebeu a notícia de que estava escrevendo um livro ressaltando o ceticismo e o desprezo que a notícia recebeu da parte dos homens: "Muitas pessoas acreditavam e ainda acreditam que a mulher não é capaz de escrever mais do que poeminhas de amor e cantigas de 
embalar. (...) Ainda hoje a sociedade moderna considera os artistas como seus membros marginais. Ser mulher e ser artista torna-se um verdadeiro escândalo." (CHIZIANE, 2013, p. 11 -12).

Quase vinte anos depois desse depoimento, pode ser que tenha havido alguma diferença nas concepções sociais e os preconceitos dirigidos a artistas e às mulheres tenham se transformado, mas ainda é tempo de afirmar o lugar da arte das mulheres que escrevem para viver, para sobreviver, para refletir, para resistir, para experimentar, para inventar. Clarice Lispector, Cecília Meireles, Henriqueta Lisboa, Nélida Piñon, Conceição Evaristo, Lídia Jorge, Paulina Chiziane, Maria Gabriela Llansol, Carolina de Jesus, dentre tantas outras, são mulheres que enfrentaram, pela "força mágica da criação", a discriminação da sociedade. Mulheres que se propuseram a tratar de temas diversos, os permitidos e os proibidos, e se atreveram a abordar, sem amargura, as dobras do feminino. Os traumas de guerra, a violência contra a condição da mulher, o cotidiano na miséria, as angústias com os filhos e consigo mesmas, o trabalho estético, o corpo marcado, dilacerado, emergem das escritas dessas, e de outras mulheres.

A escrita de mulheres não é fato raro, nem novo. A intensa produção literária feminina, entretanto, não se reflete no número de publicações de obras de mulheres. Deixada à margem dos processos editoriais por muitos anos, a literatura produzida pelas mulheres, em determinados momentos, ficou circunscrita à vida familiar, e tratada como uma espécie de atividade doméstica ilustrada, ou como um desabafo sem importância estética. Autoras de significativa produção literária tiveram dificuldades de publicar seus trabalhos, pelo menos até o século XX, pelo fato de a literatura de mulheres ser considerada menor. Entre as que editaram, há muitos casos em que "o tempo da edição não é o da escrita". No caso específico das escritas autobiográficas das mulheres, no período que separa a escrita e a edição "se introduzem as múltiplas intervenções que transformam uma escrita pessoal, destinada a leitores familiares e pouco numerosos num livro que resulta de um trabalho de edição feito, segundo os casos, por membros da família, pesquisadores ou 'copy editores' das editoras". (CHARTIER, In. LACERDA, 2003, p. 19). Este é o caso de Carolina Maria de Jesus, escritora mineira, da cidade de Sacramento, que completaria 100 anos neste ano, e que teve sua principal obra, Quarto de despejo, organizada e editada pelo jornalista Audálio Dantas.

Do mesmo modo em que há, ou pelo menos houve, um descompasso entre a produção literária das mulheres e o reconhecimento editorial, há, no Brasil, um silenciamento sobre essa produção em compêndios de história da literatura produzidos no século XX. Em um rápido cotejo de volumes de A literatura 
no Brasil, obra organizada por Afrânio Coutinho, publicados em 1969 e 1986, observa-se a menção a poucas autoras. Entre as mais conhecidas estão Rachel de Queirós, Cecília Meireles, Henriqueta Lisboa, Francisca Júlia e Gilka Machado. Entre as menos citadas estão Maria da Saudade Cortesão e Júlia Corteiros. Outro exemplo significativo desse silenciamento da produção literária feminina está em A literatura Brasileira através de textos, de Massaud Moisés, na qual, pelo menos no índice de nomes, não se vê menção, por exemplo, nem à poetisa potiguar Nísia Floresta e nem à mineira Henriqueta Lisboa. É uma espécie de exílio historiográfico das escritoras. Ainda nesse aspecto, fato significativo é o modo de entrada de Henriqueta Lisboa na obra de Manuel Bandeira, Apresentação da poesia brasileira. Nela, a referência à autora aparece de modo bastante sucinto: "Mineira é também Henriqueta Lisboa (1904-1985), de cuja poesia se pode dizer o que ela diz do morto no poema 'O mistério': é poderosa de indiferença e equilíbrio, completa em si mesma, torre de seduções e amarras". Continua o poeta: "E é na morte que encontra seu maior tema, a morte 'cruel mas limpa', depois da qual 'tudo volta a ser como antes da carne em desordem'.” (BANDEIRA, 2008, p. 191 - destaques do autor).

$\mathrm{Na}$ observação do poeta-crítico, nenhuma alusão ao empenho formal da escritora, à variedade temática de seus poemas, ao teor crítico e reflexivo de sua obra metapoética. Nesse mesmo trabalho, Bandeira elenca os novos escritores. Entre eles estão citadas Lucy Teixeira, Marly Oliveira e Zila Mamede, sobre as quais Bandeira afirma: "Entre os nomes femininos alguns aparecem com força, às vezes, superior à da maioria dos poetas do outro sexo."(BANDEIRA, 2008, p. 211), numa evidente hierarquização de gênero.

Para as mulheres, as interdições não estão circunscritas ao reconhecimento editorial e historiográfico. À marginalização editorial e ao silenciamento historiográfico, junta-se, no âmbito da literatura brasileira, uma espécie de interdição institucional. A presença de escritoras em órgãos de representação de classe é muito pequena, seja na União Brasileira de Escritores, seja na Academia Brasileira de Letras. A União Brasileira de Escritores, por exemplo, instituição que existe desde 1958, teve, em todo o período, apenas uma presidenta: a jornalista Helena da Silveira. No caso da Academia Brasileira de Letras - ABL -, a participação das mulheres teve início apenas na segunda metade do século XX, mesmo com o já expressivo número de escritoras reconhecidas pelo público e pela crítica. Na segunda metade daquele século é que autoras como Rachel de Queiroz, Dinah de Silveira de Queiroz, Nélida Piñon, que foi presidente da casa, Lygia Fagundes Telles, Zélia Gattai e Ana Maria Machado foram indicadas para a ABL. 
Se a conquista da notoriedade é difícil, do mesmo modo foi a conquista da escrita. Impedidas, muitas vezes, de frequentar escolas, a história da conquista da escrita pelas mulheres pode ser compreendida como tempo de transgressão, de conquista de poder e emancipação. (CHARTIER apud LACERDA, p. 20).

Mesmo com todas as interdições, os silenciamentos e a marginalização no interior dos sistemas literários a que pertencem, as mulheres se rebelam contra o preestabelecido, resistem ao preconceito e escrevem. Por meio de suas obras, testemunham um modo de existir e de estar no mundo, se debruçam sobre matérias que fazem parte do universo feminino e lançam sobre elas um olhar de mulher engajada. A mulher escreve para falar do tempo e da memória, para articular lembrança, esquecimento e imaginação. As mulheres escrevem para atuar na vida cultural, para transigir noções estéticas e históricas fixas. Escrevem para produzir atritos. As mulheres escrevem para refletir sobre o fazer poético, discutindo o processo de criação literária e seus desdobramentos. Para isso, rompem as fronteiras do lar, do mundo privado, e ocupam o espaço público, desnudam as interdições ao feminino, revelam preconceitos, propõem travessias entre a tradição e a modernidade.

É para falar do rompimento dessas fronteiras e das travessias feitas por diversas escritoras que a revista Scripta publica este volume sobre as escritas das mulheres. O periódico procura trazer diversas análises das obras de mulheres, realizadas por meio de distintas matrizes teóricas, com a intenção de mostrar como o discurso literário está em diálogo com os discursos histórico, filosófico, psicanalítico, pedagógico, político, ideológico, afetivo. Por meio da voz de críticos de diferentes instituições, a Scripta traz a preocupação de Maria Gabriela Llansol com os "nós constitutivos do texto", as figuras; a transgressão às normas de gênero presentes em Nélida Pinõn; o aconchego e afeição nos livros de literatura infantil de Clarice Lispector; as dificuldades editoriais das escritoras caboverdianas, como Dina Salústio; o trabalho formal de Adélia Prado; a força intelectual de Henriqueta Lisboa, Conceição Evaristo; o tratamento fluido e intenso dado ao tempo nas poesias de Cecília Meireles e os diálogos das escritoras brasileiras, como Cecília Meireles e Henriqueta Lisboa, com autoras latino-americanas.

Além da força da escrita dessas mulheres, neste número, o periódico homenageia duas escritoras negras, uma brasileira, outra moçambicana: Carolina de Jesus, que faria 100 anos em 2014, e Paulina Chiziane, que fará 60 anos em 2015. São duas mulheres que experimentaram o sonho da escrita e, por ele, viveram toda sorte de discriminação.

A homenagem a Paulina Chiziane, moçambicana, nascida em 1955, e 
reconhecida como a primeira mulher daquele país a escrever um romance, concentra-se no estudo de sua obra Ventos do Apocalipse, analisada sob diversos aspectos. Denise Borille de Abreu compara e contrasta a maneira imaginada como a protagonista Minosse, desse romance de Chiziane, e Eva Lopo, personagem de A costa dos murmúrios, da escritora portuguesa Lídia Jorge, descrevem a nação moçambicana antes e depois da guerra colonial, e como elas narram o trauma vivenciado nessa guerra estabelecendo um interessante diálogo entre as duas literaturas. Assunção de Maria Souza e Silva lê a mesma obra de Chiziane para tratar da condição feminina no romance por meio do estudo das personagens Minosse e Emelina, numa tentativa de perceber como as figuras femininas atravessam a narrativa desempenhando a função de estabelecer a relação entre a tradição e a modernidade, no quadro em que a condição é profundamente marcada pelo esfacelamento do ser em estado de guerra e sob o poder patriarcal. Numa outra perspectiva é o trabalho de Franciane Conceição da Silva, que se dedica a analisar aspectos estéticos e estilísticos da obra para entender o quanto ela se mostra original e inovadora"e Katya Queiroz Alencar estuda Ventos do Apocalipse a partir da hipótese de que ele "se estrutura em um eixo dialógico e deslizante de duas categorias, vida e morte, em torno do qual são tecidas imagens de violência e guerra a partir de ações que constroem a diegese do romance e reforçam um comprometimento ético da escritora com o testemunho do trauma da guerra civil vivido pelo povo moçambicano."

Esses estudos evidenciam a força da escrita de Chiziane, militante pela justiça e pela igualdade, que em 2005 chegou a ser indicada ao Prêmio Nobel da Paz, em reconhecimento ao seu trabalho, para quem a escrita trouxe uma série de conflitos: "A escrita trouxe-me uma série de conflitos na esfera familiar. Raros são os casos de mulheres que seguem a carreira artística e que possuem uma família equilibrada. Esta é a minha situação e a minha luta." Por isso, a autora afirma: "Com as minhas mãos, afasto pouco a pouco os obstáculos que me cercam e construo um novo caminho da esperança de que, num futuro não muito distante, as mulheres conquistarão maior compreensão e liberdade para a realização de seus desejos." (CHIZIANE,2013, p.14)

Igualmente conflituosa foi a dedicação de Carolina de Jesus à escrita, como será observado nos dois artigos sobre a obra dela e nas três entrevistas com seus editores aqui publicadas. Elzira Divina Perpétua em "A proposta estética em Quarto de despejo, de Carolina de Jesus", alerta-nos para o fato de que a questão estética foi sempre uma preocupação de Carolina, que possuía uma ideia bastante diferente da de seu editor a respeito do diário. De acordo com Perpétua, 
para Carolina, o diário continha temas nada relevantes sobre a favela, da qual fornecia um retrato pungente, que nunca tinha sido registrado sob aquele ângulo. Para Audálio Dantas, ao contrário, era exatamente isso o que importava, porque havia no discorrer dos temas a expressão estética que causava o inesperado impacto no leitor. Porém, contrariando as expectativas de seu editor, o desejo expresso de Carolina era produzir e publicar aquilo que a transportava para longe da escrita da favela.

A produção ficcional de Carolina de Jesus, assim como suas reflexões sobre o fazer literário, foi praticamente extirpada pelo editor dos diários, sendo esta uma das razões para que seus manuscritos sejam buscados agora como fonte inesgotável de pesquisas. Segundo Elzira Perpétua, os textos que não se inserem nos planos da edição dos diários tangenciam toda a escrita do cotidiano; e a escrita diária é, de certa forma, movida pelo desejo de Carolina de ver sua obra ficcional publicada. Para Perpétua, a força poética de Carolina resiste também em Quarto de despejo. Em suas páginas repercute uma representatividade coletiva, que outorga ao diário uma função social, fazendo sobressair o gesto solitário de Carolina, para quem escrever funciona menos como ato de catarse do que como forma de resistir à miséria.

Em seu livro A vida escrita de Carolina de Jesus, publicado neste ano de 2014, Perpétua explica que descobriu os diários de Carolina no início da década de 1990 e ao cotejá-los com os manuscritos se deparou com indicações de que ela também produzia textos ficcionais e tentava obstinadamente publicá-los. Algumas dessas produções viriam a público ainda nos anos 1960, com recursos da própria autora, como o livro Provérbios, o romance Pedaços da fome e o disco Quarto de despejo, ou em publicações esparsas, como o conto "O japonês", na revista Cláudia, e "Onde estais felicidade", no jornal Movimento. Por fim, sua Antologia pessoal, seleção de poemas organizada por Carolina antes de sua morte, ocorrida em 1977, só seria conhecida em 1996, graças à persistência do pesquisador da área de História, José Carlos Sebe Bom Meihy, junto à família da autora.

Além da polêmica referente à publicação de Quarto de despejo: diário de uma favelada, e à força estética da obra ficcional de Carolina, Scripta discute a edição e tradução de outra obra da autora: Diário de Bitita, publicada no Brasil em 1986, com direitos adquiridos da edição francesa Journal de Bitita, de 1982. A história da publicação dessa obra, suas traduções para o inglês e para o francês e os percursos dos manuscritos estão discutidos no artigo de Raffaella Fernandez e Sueli Meira Leibig e nas entrevistas realizadas por Raffaella Fernandez com os editores do livro, na França. No artigo, as autoras comparam a versão brasileira 
de Diário de Bitita, de Carolina Maria de Jesus e sua tradução para o inglês americano feita por Emanuelle Oliveira e Beth Joan Vinkler, intitulada Bitita's Diary: the childhood memoires of Carolina Maria de Jesus." Fernandez e Leibig observam "em que medida a subjetividade das tradutoras da obra para a língua inglesa produziu efeitos de sentido e de que maneira essas possíveis interferências podem vir a afetar o leitor."

Espera-se que essas homenagens e os estudos acerca das escritas das mulheres contribuam para que um maior número de leitores tome contato com a obra daquelas que, com sua escrita, lançam, "na terra fértil, a semente da coragem e da vontade"e que lutam "por uma nova visão do mundo", para transformar o cotidiano de sofrimento e incertezas, com sua força e rebeldia. (CHIZIANE, 2013).

Referências

CHIZIANE, Paulina. Eu mulher... por uma nova visão do mundo. Belo Hoizonte: Nandyala, 2013.

JESUS, Carolina Maria de. Quarto de despejo: diário de uma favelada. São Paulo: Francisco Alves, 1960.

PRADO, Adélia. Bagagem. 2 ed. Rio de Janeiro: Nova Fronteira, 1979.

LACERDA, Lilian de. Álbum de leitura: memória de vida, história de leitores. São Paulo: Editora da UNESP, 2003.

COUTINHO, Afrânio. Org. A literatura no Brasil.Vol IV. Rio de Janeiro: Editorial Sul Americana, 1969.

COUTINHO, Afrânio. Org. A literatura no Brasil.Vol V. Rio de Janeiro: José Olympio, EDUFF, 1986.

MOISÉS, Massaud. A literatura brasileira através de textos. 20 ed. Revista e ampliada.

São Paulo: Cultrix, 1997,98,99.

BANDEIRA, Manuel. Apresentação da poesia brasileira: seguida de uma antologia/ posfácio de Otto Maria Carpeaux - São Paulo: Cosac Naify, 2009.

PERPÉTUA, Elzira Divina. A vida escrita de Carolina Maria de Jesus. Belo 
Horizonte: Nandyala, 2014a.

PERPÉTUA, Elzira Divina. Carolina de Jesus: pensamento poético, linguagem clássica e ideal de vida. Texto apresentado no VI Colóquio Mulheres em Letras. Belo Horizonte: FALE/UFMG, maio 2014b (inédito). 


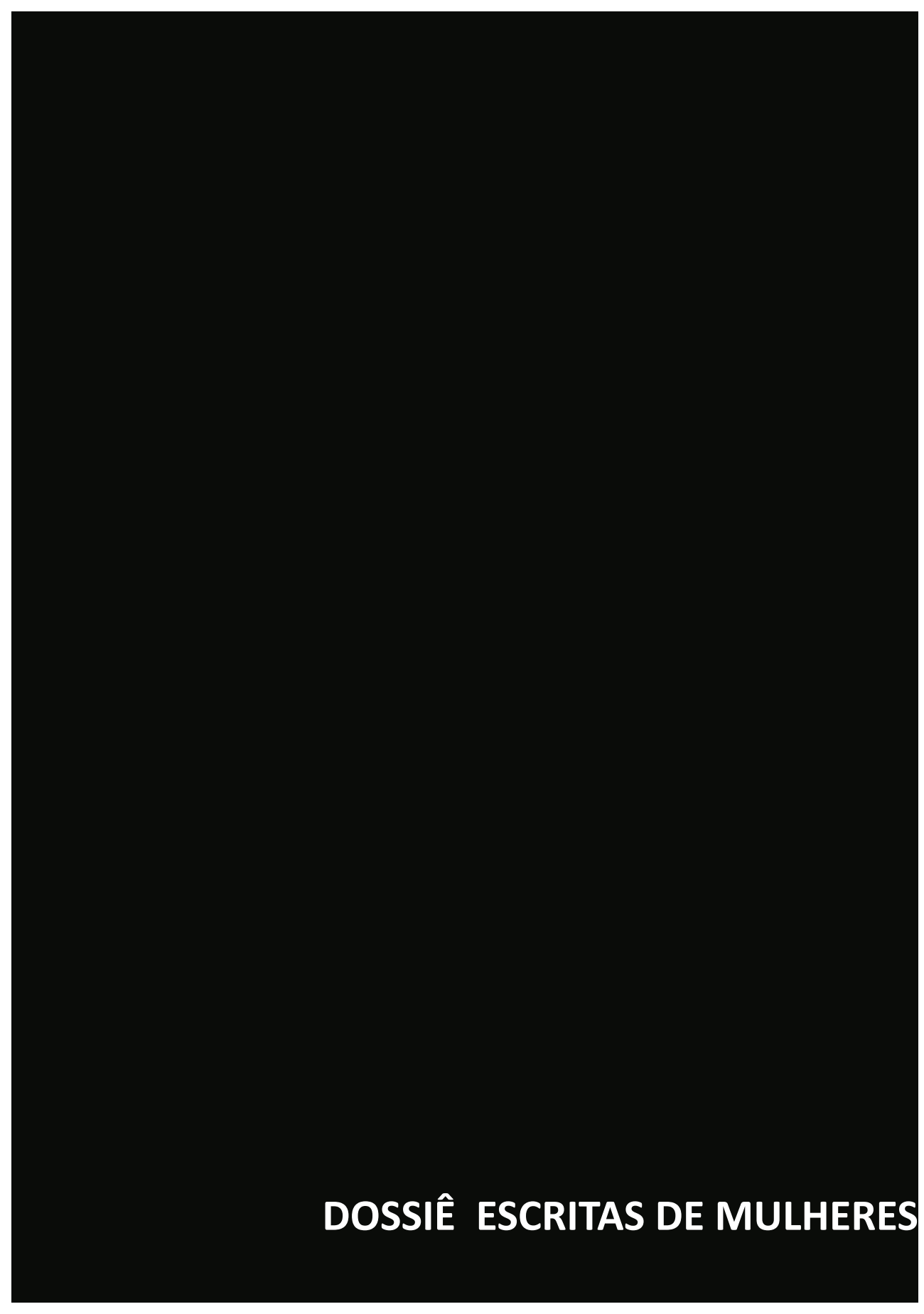


